\title{
De rockeros y neojarochos. Culturas juVEniles y lóGiCas DE DESARrollo CUltural en la XaLAPA CONTEMPORÁNEA
}

\author{
Homero Ávila-Landa
}

Resumen: Agregadas en diferentes tipos de colectividad, en Xalapa, Veracruz se expresan particulares manifestaciones juveniles -identidades, culturas, tribus, subculturas, contraculturas, ciberculturas - quemuestran la complejidad de la vida social ligada a la globalización cultural. En términos de diversidad, la ciudad es laboratorio y escenario de múltiples representaciones juveniles donde se experimentan y exhiben culturas e identidades cuyas formas de ser son distintas en sus modos de relación con el Estado cultural, como el rock, distante de las políticas culturales oficiales, y el son jarocho "tradicional", más ligado a la intervención cultural. Ambas son alternativas identitarias entre las juventudes de la ciudad.

Palabras clave: culturas juveniles, identidades juveniles, rockeros, neojarochos, desarrollo cultural.

Enviado a dictamen: 20 de junio de 2012

Aprobación: 25 de julio de 2012

Revisiones: 1

Dr. Homero Ávila Landa, doctor en antropología social por el Centro de Investigaciones y Estudios Superiores en Antropología Social (CIESAS). Temas de especialización: estudios sobre juventudes y el análisis de la relación sociedadEstado de las políticas culturales. Correo electrónico: havilanda@gmail.com
Abstract: In Xalapa, Veracruz the varied expressions of youth culture -identities, tribes, subcultures, countercultures, cybercultures - organized in different types of collectivities, demonstrate the complexity of social life linked to processes of cultural globalization. In terms of diversity, the city functions as a laboratory, scene of multiple youth representations that differ in their modes of interaction with the State: while "traditional" son jarocho, for example, is closely intertwined with official cultural policies, rock, in contrast, has little interaction with them. Yet both forms flourish as alternative forms of identification among the city's youth.

Keywords: youth cultures, youth identities, rockers, neojarochos, cultural development.

\section{Juventud/es: diversidad, transitoriedad, condiciones}

$\mathrm{E}$

n términos socioculturales, más que hablar de juventud $^{1}$ en singular, es pertinente hablar de juventudes en plural, pues el estado transitorio que define a la juventud asume formas particulares en contextos y relaciones sociales específicos; además porque las condiciones de género, clase, etnicidad, generación, y la situación rural y/o urbana, inciden en su constitución, características y formas de experimentar 
la vida social. La juventud, entonces, no se representa ni se vive de una única forma; es un fenómeno diverso y relacional que adquiere sentido en su contexto, esto es, dentro de las estructuras sociales, también cambiantes, donde se inserta (Feixa, 2006; Valenzuela, 2009).

A mediados del siglo XX, ya como objeto sustantivo de mediación comunicacional masiva y de las industrias culturales modeladoras de imágenes e imaginarios de/sobre la juventud y lo juvenil generalizadas en Occidente (Levi y Schmitt, 1996), el tema de las juventudes pronto se posiciona en ámbitos como la opinión pública, las instituciones estatales formadoras de ciudadanos y su memoria histórica - como el sistema educativo - o atingentes al control social sistema de seguridad pública-. En ese contexto, la construcción social de la categoría contemporánea de juventud en México se asocia con la emergencia de una primera subcultura juvenil: los rocanroleros o rebeldes sincausa, a quienes les suceden los rockeros y diversas identidades juveniles (Domínguez, 2012; Arana, 2002; Urteaga, 1998).

En el país, el estudio sobre las culturas juveniles se acentúa hacia la segunda mitad de los años ochenta; ${ }^{2}$ entonces, una nueva generación de científicos sociales escudriñó las bandas juveniles, ${ }^{3}$ surgidas entre sectores populares y territorializadas en barrios emergidos en un contexto de crisis económica que las condicionaba a la marginación, la pobreza y la exclusión social. ${ }^{4}$ Para los sectores conservadores y los medios masivos de la época, los banda se distinguen por su comportamiento violento. ${ }^{5}$ Las visiones desviacionistas del comportamiento juvenil con que, académicamente, se observó a las bandas, serán reemplazadas o cuando menos complementadas por perspectivas culturalistas que se cuidan no de estigmatizarlas sino de ilustrar sobre la diversidad juvenil. ${ }^{6}$

Desde entonces en la, transición de los años ochenta a noventa del siglo XX, una distinción primaria establece que, en la vida social, las juventudes se representan mediante distintas imágenes y valoraciones que fraguan en estereotipos capaces de adjudicar valores positivos y negativos a determinados tipos de juventud. Así, hallamos asociaciones virtuosas como las que se dan entre juventud y mundo del deporte, educación y trabajo; o asociaciones viciosas como las ligas entre juventud y mundo adulto, violencia, drogas, crimen o prácticas sexuales de riesgo. Quizá la categoría mediática, que no académica, de ninis (jóvenes que ni estudian ni trabajan), actualiza aquellas asociaciones estereotípicas de las juventudes; pero, en todo caso, no las elimina.

\section{Culturas e identidades juveniles}

A la diversidad juvenil corresponden también multiplicidad de posturas y filiaciones teóricoconceptuales mediante las que se ha abordado su devenir. Por su cualidad abarcadora para asir la complejidad sociocultural juvenil, han sido influyentes en el terreno académico y político-institucional los conceptos de culturas juveniles y de identidades juveniles. ${ }^{7}$

Las culturas juveniles, define Feixa:

En un sentido amplio..., se refieren a la manera en que las experiencias sociales de los jóvenes son expresadas colectivamente mediante la construcción de estilos de vida distintos, localizados fundamentalmente en el tiempo libre, o en espacios intersticiales de la vida institucional. En un sentido más restringido, definen la aparición de 'microsociedades juveniles', con grados significativos de autonomía respecto de las 'instituciones adultas', que se dotan de espacios y tiempos específicos, y que se configuran históricamente en los países occidentales tras la segunda guerra mundial, coincidiendo con grandes procesos de cambio en el terreno económico, educativo, laboral e ideológico. Su expresión más visible son un conjunto de estilos juveniles 'espectaculares', aunque sus efectos se dejan sentir en amplias capas de la juventud... (Feixa, 2006: 106). ${ }^{8}$ 
Las culturas juveniles hablan de complejidad sociocultural pues: "no son homogéneas ni estáticas: las fronteras son laxas y los intercambios entre los diversos estilos, numerosos" (Feixa, 2006). En cuanto a su identificación, estas culturas son volubles en función de las influencias a que se ven expuestas y de las "resoluciones" alcanzadas en sus construcciones identitarias. Las culturas juveniles, ubicadas en el plano de las imágenes culturales, hacen referencia a los "estilos más o menos visibles que integran elementos materiales e inmateriales heterogéneos provenientes de la moda, la música, el lenguaje, las prácticas culturales y las actividades focales" (Feixa, 2006: 108-109).

Puesto que sobre todo rockeros y neojarochos son asibles mediante la noción de estilo juvenil, subrayo la relevancia de la música para las culturas juveniles, al punto de que algunas se fundan en torno a corrientes musicales específicas, como es el caso de los rockeros, darketos, punks, metaleros o heavy-metaleros o grungeros. Como se infiere, en esas culturas, una actividad focal aunque no exclusiva es la producción, circulación y consumo de la música que las nombra - aunque bien pueden gustar y participar de otros géneros musicales y adscribirse a otras culturas y simbologías juveniles -.${ }^{9}$ Es de subrayar que la emergencia y concreción de la juventud como tema generalizado, realidad empíricamente demostrable y categoría de análisis científico, encuentra vínculos con el rocanrol y el rock y sus ramificaciones músico-culturales. Al cabo, como reconviene Feixa, quien igualmente remarca el continuum música-identidad-cultura juvenil, las juveniles son culturas que no pueden pensarse ni analizarse al margen de la cultura hegemónica, las culturas parentales y generacionales con las que se relacionan y entre las que adquieren sentido.

Por otra parte, siguiendo a Valenzuela (2009), las identidades juveniles forman parte de las identidades sociales en tanto
... refieren procesos intersubjetivos inscritos en relaciones sociales históricamente situadas, por lo cual refieren a interacciones y representaciones complejas de lo individual y lo colectivo, pues la condición juvenil sólo adquiere sentido en el contexto social más amplio y en su relación con lo no juvenil (Valenzuela, 2009: 36).

Además, esas identidades aluden

... a procesos de disputa y negociación entre las representaciones dominantes de la juventud, que son hetero-representaciones externas sobre los jóvenes, aunque muchas ocasiones ellos mismos se sumen a estas representaciones (Valenzuela, 2009: 36).

Contraparte de esa presión exterior que intenta establecer lo que la juventud es o debería ser, es la autopercepción, que es definición del nosotros jóvenes, rockeros, punks, etcétera. De ello se colige que:

Las identidades juveniles remiten a la construcción de umbrales simbólicos de adscripción o pertenencia, en los que se delimita quiénes pertenecen al grupo juvenil y quiénes quedan excluidos (Valenzuela, 2009: 37).

Aquí las complejidades encarnadas en las identidades sociales como en las juveniles están marcadas por el hecho de ser relacionales -interaccionan con otros ámbitos sociales y sus dimensiones socioeconómicas, de género y étnicas - y cambiantes - "se construyen y reconstruyen en la interacción social"-. Además "se construyen en ámbitos íntimos de intensa interacción" (cuyos referentes son la familia y el barrio), y también "a partir de relaciones sociales inscritas en redes de poder" (Valenzuela, 2009: 36-37).

Cercano al planteamiento de Gilberto Giménez (2009) sobre las identidades sociales, Valenzuela resalta el hecho de que algunas identidades juveniles, al estar inscritas en relaciones sociales y por ser 
representaciones disputadas entre grupos y sectores de la sociedad, llegan a experimentar la estigmatización. ${ }^{10}$ El propio Valenzuela propone una tipología que relaciona juventud, grupos dominantes y estructuras sociales. ${ }^{11}$ Habla de 1) Identidades proscritas; ${ }^{12}$ 2) "Grupos tolerados", ${ }^{13}$ y 3) "grupos fomentados. ${ }^{14}$

Esta clasificación da pie para hablar con brevedad de dos expresiones juveniles contemporáneas asentadas en la ciudad de Xalapa, Veracruz, México. Una, la rockera, ha manifestado formas y experimentado valoraciones que por periodos la colocan como expresión del tipo 1, identidades proscritas; otra, la neojarocha, por el manifiesto impulso estatal mediante políticas culturales, estaría en el grupo 3, la de los grupos fomentados.

\section{De rockeros y neojarochos}

Xalapa, capital del estado de Veracruz, es teatro de diferentes culturas, identidades y prácticas juveniles; la ciudad compone un sensible escenario donde tienen lugar representaciones juveniles que agregan riqueza a la diversidad cultural de la entidad. ${ }^{15}$ Observamos allí culturas asociadas con géneros musicales, como el rock (rockeros, metaleros, punks, darketos, emos...) además de otras centradas en prácticas descritas por sus nombres: patinetos o eskatos y grafiteros; también hallamos la cibercultura blogger, y expresiones como el complejo cultural del hip hop integrado por grafiti, rap y break dance, con sus expresiones escrita, lírica y bailable. Igualmente en la ciudad, como expresión marcadamente juvenil de nuevo cuño, sobresale la identidad neojarocha basada en la recreación musical del son jarocho y en la fiesta del fandango "tradicionales". ${ }^{6}$

Es de notar que mientras el rocanrol en Xalapa tiene lugar desde los primeros años sesenta, los neojarochos como los llama una integrante connotada de la escena fandanguera en lo que significa un momento de expansión del son jarocho que lo tiene como expresión cultural local-global, se posicionan en el panorama musical-cultural de la capital hacia mediados de los años noventa. No es interés del artículo exponer en demasía el perfil de ambas manifestaciones, sino apenas apuntar algunas claves que develen las lógicas y razones que animan el desarrollo de ambas expresiones a partir de sus formas diferenciadas de relación con las políticas culturales locales, basadas en visiones del mundo particulares que definen sus vínculos con el Estado. A su manera, el ejercicio es un acercamiento a las formas y sentidos de interrelación entre culturas y políticas culturales.

\section{Lógicas de desarrollo cultural: rockeros y neojarochos en Xalapa}

\section{Rockeros}

La escena rockera xalapeña, que ya rebasa las cinco décadas, se compone de diferentes generaciones que desde los tempranos años sesenta se suceden incesantes hasta configurar el rock en o de Xalapa. Desde la primera mitad de ese decenio, con los Jetters, Zipper's y Stranger, animados por los entonces muy jóvenes precursores del ritmo en la ciudad, el rocanrol sienta sus reales e inaugura una nueva representación de la juventud local. La asociación juventud y rocanrol en ese tiempo pareció natural puesto que esa música distinguió un nuevo modo de ser joven en la época. Rocanrolero fue equivalente de joven, no había rocanroleros adultos, al menos del modelo de juventud asociada con los estereotipos culturales provenientes del cine y el rock and roll estadounidense (Arana, 2001; Urteaga, 1998; Monsiváis, 1986 y 1988). El quehacer de esas bandas se centró en la recreación de covers o refritos (traslados al español de éxitos estadunidenses del género) de versiones rocanroleras mexicanas hechas por agrupaciones como los Teen Tops, Black Jeans, Rebeldes del rock, Boppers, Hooligans, Spitfires o los Crazy Boys..., quienes a su vez copiaban/ adaptaban el rocanrol estadounidense de los años cincuenta. 
Como toda cultura, la rocanrolera debió ocupar y/o generar espacios para la recreación de sus prácticas y, por tanto, de su identidad. Cafeterías con rockolas, tardeadas, celebraciones carnestolendas, estaciones de radio y fiestas familiares, fueron sus territorios más comunes. Una nueva imagen, nuevos comportamientos, gustos y lenguajes, fueron complemento de quienes se adscribieron al nosotros rocanroleros en esa capital. En lo sucesivo, otras expresiones culturales configurarán sentidos, valores, visiones del mundo, prácticas, tiempos y espacios, que los proveerán de identidad en tanto jóvenes y rockeros. ${ }^{17}$

Entre los años sesenta y ochenta, fueron presa de estigmatización — cristalizada en la frase "sexo, drogas y rocanrol" asignada a la actitud considerada rockera- y censura por parte del mundo adulto o lo que representara el orden establecido; situación que empezó a superarse con el advenimiento hacia 1986 del proyecto comercial "Rock en tu idioma" de la disquera BMG Ariola para Latinoamérica, que también implica el deslizamiento de un rock marginado y popular a otro público, masivo, accesible, y de/para diferentes sectores económicos. En ese momento, en el país, la apertura cultural de la que formaba parte el rock, provino centralmente del mercado y no del Estado todavía garante del nacionalismo cultural homogeneizador, pero que se había mostrado lento al incluir en sus políticas culturales las expresiones de la diversidad cultural, particularmente la cultura juvenil del rock que entendía como entrópica, desviada y violenta y que, por tanto, había venido reprimiendo incluso mediante el sistema policiaco. ${ }^{18}$

El impulso al rock en castellano derivado de "Rock en tu idioma" reveló que durante largos años (en Xalapa de 1975 a 1985 aproximadamente), en el subterráneo, había crecido la diversidad sonora y se habían multiplicado las escenas rockeras fuera de las grandes ciudades del país: se vio entonces que las había también local-regionales. Es el caso de Xalapa donde, desde los años sesenta hasta hoy el rock continúa siendo alternativa cultural e identitaria juvenil y transgeneracional (Ávila, 2001).

Desde que Jetter's comienza a tocar en la Xalapa de inicios de aquella década, el impulso del rocanrol ha estado más cercano a la autogestión como esfuerzo personal, de amigos, familiares y pequeños propietarios de antros, ${ }^{19}$ que a cualquier otro tipo de apoyo proveniente de las estructuras sociales dominantes. Que el rock haya sido clasemediero explica en parte la capacidad de hacerse socialmente visible en tanto práctica juvenil. Esta visibilidad se debe a que los espacios del rock local han sido preferentemente escuelas, antros, reuniones y, ocasionalmente, algún festival oficial centrado en el rock o en eventos donde éste tiene cabida; también ocasionalmente el rock se ha apropiado de espacios públicos: parques, plazas, calles.

Resulta significativo aún hoy que, tanto en su producción como en su consumo, esa cultura juvenil se recrea al margen, e incluso en contra, de lo aceptado y de los poderes político y social. Aunque el rock es algo más bien aceptado, su gramática derivada de una ideología contracultural sigue enfatizando rechazo y crítica al orden social imperante; esa ideología también es posible plasmarla en las letras ya que, a diferencia de expresiones musicales tradicionales, el rock local, sobre todo en los años noventa, se propuso la creación propia, y no únicamente reproducir obras consagradas; la innovación ha sido una de las rutas de la escena en Xalapa desde los años sesenta. ${ }^{20}$

Por otra parte, la represión y censura impuestas en algunos periodos de su historia local, provenientes de una visión estatal que asoció juventud y rock con desorden, violencia y criminalidad, así como de la postura del antiimperialismo cultural que vio en cada rockero un apátrida, justificaron visiones críticas del Estado hacia el rockero: el rock no creaba antimexicanos, en cambio, podía ser alternativa de crítica a la cultura y la política establecidas. ${ }^{21}$ En la producción de esta imagen y en el rechazo activo del rock, sobre todo entre los años sesenta y ochenta, 
formaron parte, por razones distintas, la derecha y la izquierda culturales, además de las figuras de autoridad. ${ }^{22}$ Durante ese lapso, su condición local, - a pesar de que la vitalidad y tenacidad rockera habían generado espacios alternativos a los canales institucionales y apartados de la moral local más bien conservadora - es subalterna y distante de las políticas culturales. Será así a pesar de que se ha visto representar menos que esporádicamente en festivales temáticos y en espacios oficiales como el Ágora de la ciudad, el parque Juárez o los bajos del palacio municipal, entre otros. ${ }^{23}$

A lo largo de cincuenta años esa autogestión, entendida como el empleo de recursos materiales y simbólicos, comunicacionales y expresivos, autónomos del apoyo estatal a sus creadores y seguidores, han hecho que el rock recurra a festivales escolares, bares, discotecas y negocios orientados a la juventud y a fiestas familiares; o a la reutilización de talleres, gimnasios y auditorios de distinto tipo.

La autogestión llegó a su punto más notorio a mediados de los años noventa, cuando el interés rockero rebasó la acción de individuos y de bandas aisladas, para pasar a la organización del colectivo DinámicaSonoro que, si bien efímero y de logros magros, logró proyectar el rock de la zona y del estado como un proyecto singular de colectivismo cultural. En ese proyecto sobresalió el liderazgo del grupo Aleaciones, quien convocó y coordinó los dos conciertos masivos que lograron realizar en la zona.

Después de esa experiencia, el rock volvió a su diseminación habitual, lo que le da su aspecto subterráneo y a veces discontinuo, por cuanto su presencia en la ciudad es a veces invisible y a veces notoria. El rock de bandas y públicos locales es también una escena-red con tintes transgeneracionales y parentales. La dinámica rockera se confecciona a base de relaciones entre bandas, rockeros y seguidores del género, así como entre generaciones pasadas y presentes a veces con relaciones parentales. Aún hoy depende de la autogestión que ocasionalmente alcanza cierto nivel de organización colectiva para celebrar conciertos maratónicos en plazas públicas o en bares que también a veces los acogen, guiados más por el cálculo comercial que por el interés en el fomento cultural.

Neojarochos: identidad compuesta por practicantes del son y el fandango jarochos radicados en Xalapa

Es tal la relevancia actual del son en tanto elemento de identificación para infinidad de jóvenes veracruzanos, mexicanos y extranjeros, asentados dentro y fuera del Sotavento y del país, que pasa por cultura multilocalizada. Sólo para repetir lo sabido y consignado, fuera de esa región pero dentro de nuestra entidad, tenemos neojarochos en Xalapa, Córdoba, Orizaba y, fuera de ella, los hallamos en el Distrito Federal. Fuera de México sobresale principalmente el movimiento jaranero de California, en EE.UU., sin ser la única la escena de la ciudad de Los Ángeles. La multilocalizacion del son ocurre en el marco de la globalización que pasa por la cultura y en su fase actual se dispersa mediante el movimiento jaranero que viene impulsando la revitalización del son y el fandango jarochos desde finales de los años setenta del siglo XX.

No se plantea que los neojarochos compongan una cultura o tribu juvenil, aunque tengan visos de ello; en cambio, el neojarocho puede representar una identidad en formación -empíricamente expresada como "ser jaranero" o fandanguero-, a la que centralmente, y cuando menos en Xalapa, se adscriben jóvenes de clase media y alta.

Aunque un poco antes el grupo Híkuri tocaba son jarocho en esa ciudad, la producción de generaciones neojarochas alcanza un punto clave con la llegada a inicios de los años noventa de quienes integraron al primer Son de Madera. Entonces, por razones escolares - cursar la carrera de antropología y la de historia respectivamente-, coinciden en la ciudad Rubí Oseguera Rueda y Álvaro Alcántara, jóvenes 
para entonces avezados en la promoción y recreación de son y fandango en su zona de origen, el corredor Minatitlán-Coatzacoalcos. Esta labor la continuaron temporalmente por otros medios, incluida la promoción cultural estatal en distintos órdenes de gobierno: Dirección General de Culturas Populares y Consejo Nacional para la Cultura y las Artes, además de hacer promoción internacional, en el caso de Oseguera, y nacional —en el Conaculta-, en el caso de Alcántara.

El Patio Muñoz, viejo vecindario capitalino, fue el sitio donde se asentó el proyecto de promoción y difusión del son jarocho encabezado por Ramón Gutiérrez. Allí se han impartido talleres de jarana y requinto, laudería y zapateado, y se han celebrado por años, más antes que ahora, fandangos masivos y festivales, el primero a finales de 1994. En el presente, muchos jóvenes formados en los talleres de son del Patio integran grupos del género, comandan conciertosfandangos y hacen presentaciones en antros de la ciudad y fuera de ella. Teniendo primero a Laura Rebolloso como maestra desde finales de los años noventa hasta avanzado el primer decenio de siglo XXI, ha habido otros instructores hasta el actual Tacho Utrera (del grupo Los Utrera) y los hermanos Sael y Saúl Bernal. El taller de son jarocho del Centro Escolar Xalitic ha forjado varias generaciones de secundarianos que hoy son fandangueros habituales.

Por su parte, Rubí Oseguera ha sido instructora de zapateado, investigadora de estilos de este componente del complejo fandanguero en las subregiones del Sotavento organizadora de fandangos y presentaciones de grupos en la ciudad, el estado, el país y el extranjero; aunque desde hace más de un lustro continúa su labor en ciudad de México, aún suele llevar eventos de son a Xalapa y ocasionalmente imparte talleres allí. Su quehacer de promoción ha sido retomado por diferentes creadores de son jarocho de la ciudad o avecindados temporalmente en ella.

A la migración de fandangueros de los primeros noventa, le han sucedido otras. En el presente, la escena neojarocha de Xalapa está siendo animada por jóvenes recientemente llegados del sur del estado -Cosoleacaque, Jáltipan, Acayucan, Minatitlándonde formaban parte de conjuntos jaraneros: hay ex-Cojolites, ex-Pájaros del alba, y otros que no necesariamente pertenecieron a grupos reconocidos, o ni siquiera desconocidos pero que son fandangueros de "toda su vida". En el presente, Son de Madera, Sonex y Los Macuiles son grupos representativos del son de la ciudad, así sea que en ellos converjan polémicas sobre la calidad tradicional de su obra, como antes lo han sido otros cuya desaparición no ha implicado el alejamiento de sus miembros de la escena fandanguera xalapeña.

Por otra parte, la cultura neojarocha algo tiene de cibercultura, pues mucha de su retroalimentación pasa por la carretera virtual, como lo ejemplifica el grupo yahooamigos del son jarocho y el uso de Facebook y Myspace por parte del Movimiento Jaranero, intensificado con el uso de esa plataforma comunicacional que es medio y complemento del colectivismo cultural neojarocho. Por Internet se comparte información relativa al son en general y a asuntos particulares del devenir de esa práctica cultural: allí se intercambia información sobre personajes y comunidades, formas de tocar el son, afinar jaranas, construir instrumentos del género, por ese medio se informa de eventos, se comparten décimas y sones, se ofrecen productos soneros, se discute sobre el deber ser del Movimiento o del son jarocho, incluso se arropan causas concretas en favor del son y hasta se delinean nuevas formas para una comunidad fandanguera localglobal.

Los espacios de escenificación del son en la ciudad son múltiples y sobre todo visibles, destacando negocios y aquellos de naturaleza estatal dispuestos en el marco de programas culturales municipales como el del trienio actual (2010-2013), que tiene a la nueva plaza del mercado San José y al Centro Recreativo Xalapeño como lugares notorios para el son; o el del 
trienio anterior (2007-2010), mediante el programa "Son y danzón en el árbol", en la Plazuela del Carbón. En lo que va del siglo, la asociación Culturaama es la más visible promotora de expresiones populares, preferentemente del son jarocho. El son es invitado común en los programas culturales estatales de los tres órdenes de gobierno de la ciudad, donde capitalizan espacios e infraestructura del sistema cultural municipal. El son también ha viajado a veces con apoyo estatal por otros países y su aceptación es tal que está presente en inauguraciones y clausuras de eventos varios, ya sea en calidad de protagonista o como parte del programa de que se trate: presentaciones de libros, congresos, exposiciones, ferias, festivales, etcétera. Se trata, pues, de una expresión socorrida y cultivada tanto para el Estado cultural y sus medios de comunicación local y estatal, como para innumerables jóvenes a quienes les es significativa en diferentes formas, hasta el punto de incluirla dentro de su construcción identitaria.

Pero el apoyo estatal al son jarocho no es propio sólo de la escena xalapeña; en gran medida su presencia, incluso allende las fronteras nacionales, se explica por el soporte de las políticas culturales, quienes lo tienen entre sus expresiones preferidas para inscribirse en el concierto multicultural de las naciones. Tal apoyo ha sido documentado en diferentes regiones, sobre todo en la zona sur que cubre la Unidad Regional Acayucan de la Dirección General de Culturas Populares y en la zona Veracruz-Boca del río donde ha sido decididamente impulsado por parte de este instituto desde sus orígenes mediante programas como Veracruz también es Caribe o Junio Musical (Delgado, 1999; García y Guadarrama, 2002; Rinaudo, 2011). Es pertinente decir que el florecimiento del son en la actualidad no se explica sólo por la firme intervención estatal de la que es objeto, sino por una complejidad de factores entre los que pueden citarse la aceptación de la diversidad musical en el mundo y un mercado cultural proveedor de experiencias culturales.

\section{Proximidad/distanciamiento y etos de las culturas frente al Estado cultural}

En el marco de las políticas culturales se observa que la intervención acusa preferencias, inercias o intereses sobre determinadas expresiones culturales, mientras otras permanecen fuera de su campo de visión-acción. Si bien la proximidad o el distanciamiento de la intervención cultural sobre expresiones específicas parece responder a la valoración corriente en favor de la diversidad cultural y a la materialización de los derechos culturales, también puede deberse a razones del etos que sustancian y movilizan las propias manifestaciones que virtualmente pueden ser objeto de intervención estatal mediante políticas culturales. Así, la proximidad o el alejamiento puede ser una decisión tomada por la administración cultural, pero también puede ser que tales decisiones no sean esperadas y bien recibidas por las "poblaciones objetivo" de tales actos. Podría ser el caso de la cultura rockera, en cuya cosmovisión histórica caben formas contraculturales, de resistencia y de alternativa cultural disidente que la llevan a no entablar vínculos con las políticas culturales. En el caso del son jarocho, por el contrario, en su revitalización han jugado un papel clave las políticas culturales enmarcadas en los paradigmas contemporáneos de los derechos culturales y de la diversidad cultural salvaguardados por el Estado.

A partir de conocimiento etnográfico (Ávila, 2001 y 2008) se bosquejan ideas sobre relaciones de cercanía y distancia entre las culturas juveniles rockera y neojarocha y las políticas culturales en Xalapa. Ello propone que el desarrollo cultural implica actores específicos cuya visión del mundo e historicidad plantean posibilidades diferentes de relación con las políticas culturales.

1. Desde la cosmovisión de las culturas. En el distanciamiento rock-políticas culturales oficiales, ha jugado un rol importante su originaria ideología cuestionadora, contestataria y desconocedora 
de los poderes, sobre todo el político en tanto ordenador hegemónico de la vida social y eje de "El Sistema" opresor de las libertades. Aún así, en la historia local encontramos reclamos informales al Estado en favor de la apertura de espacios para el rock. Las posiciones más radicales en este sentido quizá se ubican en el casi inexistente movimiento antisistema del anarcopunk en la localidad; que no es la única corriente opositora "al poder" y sus figuras de autoridad conservadora - padres, maestros, sacerdotes, policías, políticos-. Esa ideología ha alimentado visiones contraculturales en la escena local donde se ha valorado la búsqueda por ser diferente, por distinguirse exteriormente mediante el look y subjetivamente a través de la conformación de gustos y conocimientos rockeros, mientras que exteriormente se diferencia por medio de prácticas y/o conductas públicas y privadas que configuran una visión del mundo y un quehacer cultural particular diferente y opuesto a lo establecido. Así, el rockero local, sobre todo entre los años sesenta y ochenta, llegó a describirse como alternativo, contracultural, contestatario o iconoclasta.

Caso opuesto es la proximidad neojarochosEstado, cuyo vínculo se sostiene desde el discurso reivindicatorio de la tradición afincada en la cultura parental, desde la historia regional y desde la afirmación positiva de la pertenencia jarocha. Este orgullo se "siembra" discursivamente en talleres, seminarios y presentaciones o conciertos de son jarocho devenidos en espacios de promoción y difusión. En ellos se propicia una pedagogía cultural por la cual los voceros del son transmiten la valoración de las prácticas que sintetizan lo jarocho de modo que, a la identificación con esa expresión histórica, le es inherente tanto la idea de que el Estado cultural debe garantizar su derecho cultural, es decir, su cultura e identidad jarochas, cómo que es a las autoridades culturales a quienes deben dirigir sus demandas. Esto, desde el sistema cultural oficial, es legitimado y alimentado mediante la transmisión de importantes cantidades de recursos públicos.

2. Desde las políticas culturales estatales. Las políticas culturales en Xalapa han realizado poca casi nula promoción de las identidades juveniles rockeras; las fuentes de desarrollo de éstas han sido muy otras de las estatales, pues su ecología se circunscribe al ámbito parental y a un siempre errático mundo rockero comercial. Aunque ocasionalmente se ha incluido rock en algún festival oficial, es ilustrador que no haya tenido cabida en una institución académica como la Universidad Veracruzana, principal entidad abierta a la diversidad expresiva del estado, quien, sin embargo, cuenta con grupo de jazz, un mariachi, orquestas de salsa, de música popular, la Orquesta Sinfónica de Xalapa y grupos folclóricos que tocan son jarocho, además de ofrecer formación mediante un centro de iniciación musical, una facultad de música y otra de jazz. El rock, para las instituciones, sigue siendo una actividad distante que recibe atención ocasionalmente.

Otra es la situación del fomento estatal al son jarocho "tradicional" asentado en Xalapa. Su presencia obedece a factores propios de la movilidad humana histórica acrecentada en tiempos de globalización, hoy reflejada en la migración surcentro de la entidad veracruzana. El decidido interés estatal de promoverlo en la ciudad a través de instituciones como el Instituto Veracruzano de la Cultura, la Dirección General de Culturas Populares y los programas culturales del ayuntamiento, se ha dado en el marco de la revaloración, mediante políticas afirmativas de la diversidad cultural, para que el son jarocho se vea como representativo de la raíz afro y caribeña del estado de Veracruz, bien porque carezca de memoria colectiva y movimientos de base reivindicadores de la negritud, del pasado africano y caribeño o por su evolución presente. Mediante políticas culturales trienales, el ayuntamiento ha promovido el son jarocho y ha 
sido incluido protagónicamente en programas de festivales nacionales e internacionales que tienen, o han tenido, asiento en la ciudad, como los festivales Junio Musical y Afrocaribeño. Sin embargo, debe decirse que la Feria del Libro Infantil y Juvenil, además de folclor veracruzano, donde se incluye al son jarocho "tradicional" contemporáneo, sí suele programar rock local.

En ese panorama local, mientras para el rock al menos, la corriente que se reivindica contracultural, ha llegado a "naturalizarse" en la oposición al deber ser conservador socialmente imperante - vía por la cual representó un halo de modernidad cultural que trastocase el orden cultural cimentado en el nacionalismo cultural homogeneizador (Monsiváis, 1986, 2012; José Agustín, 1996; Pacini, Fernández y Zolov, 2004) —, el son jarocho, en cambio, desde finales de los años 70, y desde sus actores de base en su reivindicación de "lo nuestro", encuentra coincidencia con las políticas culturales.

Hasta aquí queda claro que hacerse y ser rockero en Xalapa, asumir esa identidad como tal, históricamente no pasa por un Estado cuyo objetivo, cuando menos desde la posrevolución hasta los años ochenta fue la conformación de una identidad nacional homogénea y desde entonces a la fecha incentivar identidades local-regionales que representen lo propio. Como ha dicho Andrés Brizuela, "El rock se aprende en la calle, no hay escuelas donde lo enseñen a tocar". Por su parte, sobre todo para los fandangueros jarochos forjados en talleres oficiales o no, además de aprender a valorar lo jarocho, se aprende la obligación estatal de desarrollar esas prácticas. Es evidente que el Movimiento Jaranero y la revitalización del son no pasan fatalmente por la intervención estatal, más bien se trata de una movilización colectiva cuyo uso es variado, y a veces político en el sentido de que se ve en movilizaciones sociales locales como el recibimiento de la marcha por justicia y dignidad, la demanda de justicia y democracia, u otras, y en movilizaciones nacionales como el plantón poselectoral de la elección presidencial de 2006, e internacionales como las que se suscitan en la rama del son jarocho/Movimiento Jaranero en Estados Unidos.

Según lo expuesto, tenemos que las lógicas de desarrollo de rockeros y neojarochos en Xalapa obedecen a etos o cosmovisiones a las que se asocian culturas políticas que definen formas de comportamientorelación con el Estado. Así, la cultura juvenil del rock ha implementado formas de autogestión distanciadas de las políticas culturales, hecho que libera su devenir de regionalismos y del nacionalismo cultural. En tanto la neojarocha, de los años noventa en adelante ha permanecido cercana a esas políticas respondiendo exitosamente al interés de lo mexicano y lo veracruzano, incluido lo afromexicano y lo caribeño. Empíricamente encontramos que, en algún momento de la historia del rock en la ciudad, una lógica fuerte fue existir contra el Estado, mientras que la floreciente fase actual del son en Xalapa no se explica al margen de la intervención oficial.

Tendríamos entonces formas de desarrollo entre culturas juveniles que, por contestatarias y disidentes al poder instituido, se alejan de las políticas culturales y optan por formas de autogestión liberadas de la visión y decisión estatal; y culturas más afines al espíritu de esas políticas, cuyo desarrollo componen círculos virtuosos entre la intervención y la revitalización culturales, como ocurre en el caso de diferentes culturas populares.

\section{Notas}

${ }^{1}$ Siguiendo a Feixa (2006), ésta se entiende "como la fase de la vida individual comprendida entre la pubertad fisiológica (una condición 'natural') y el reconocimiento del estatus adulto (una condición 'cultural'), la juventud ha sido vista como una condición universal, una fase del desarrollo humano que se encontraría en todas las sociedades y momentos históricos. Según esta perspectiva, la necesidad de un periodo de preparación entre la dependencia infantil y la plena inserción social, 
así como las crisis y conflictos que caracterizarían a este grupo de edad, estarían determinados por la naturaleza de la especie humana" (Feixa, 2006: 16).

2 Ello coincide o quizá se relaciona con la celebración en 1985 del Año Internacional de la Juventud, designado por la Organización de las Naciones Unidas, y responde a la relevancia que decenios atrás había ganado la juventud como actor social y agente de cambio, sobre todo sociocultural.

${ }^{3}$ Se trata de un conjunto de investigadores que habrán de coincidir, por sus publicaciones o por trabajo institucional, en torno al Instituto Mexicano de la Juventud, como el catalán Carles Feixa y los mexicanos José Manuel Valenzuela Arce, Rossana Reguillo Cruz, José Antonio Pérez Islas, Maritza Urteaga y Alfredo Nateras, entre otros.

${ }^{4}$ Célebres en ese momento, la banda de Los Panchitos. "Hacer panchos", se estableció entonces, como hacer líos. Para el tema, véase León (1985), García Robles (1990) y Gomezjara, et al. (1993).

${ }^{5}$ Para tener un panorama sobrela tensión entrelas visiones desviacionistas y la contrapropuesta culturalista, véase Gomezjara (1993), Valenzuela (1988) y García Robles (1990).

6 El crecimiento de saberes científicos sobre las juventudes en México, no es casual. En ello resulta curiosa la aparición de tres obras que en un mismo año marcan la nueva etapa académica en el país de los estudios de juventudes, fuertemente impulsada por el Instituto Mexicano de la Juventud durante el último decenio del siglo pasado. Me refiero a A la brava ése!, del mexicano José M. Valenzuela Arce, a El tiempo de las tribus, del francés M. Maffesoli y La tribu juvenil, del catalán Carles Feixa.

${ }^{7}$ Aquí cabe enlistar otros términos en boga en estos estudios socioculturales, tales como subculturas o culturas subalternas, contracultura, ciberculturas, tribus y generaciones. Feixa (2006) indica que su noción de culturas juveniles correspondería al de subculturas o culturas subalternas, contraparte de una hegemonía dada; por tanto, serían culturas contestatarias al poder instituido, hegemónico en un tiempo y espacio acotados. Tampoco utiliza el término contracultura por tener la carga de representar una época - la contracultura de los años sesenta, que fue alternativa social, política, económica y cultural a la sociedad convencional- y no necesariamente prácticas o proyectos alternativos posteriores a ese decenio, aunque también pudiera recuperar este punto. Por otro lado, las ciberculturas juveniles son aquellas prácticas gregarias y de nueva socialidad basadas en el uso de las nuevas tecnologías informáticas y comunicacionales. Por su parte, Maffesoli (2004) redefine el concepto tribus con fines heurísticos para hablar de formas de organización y manifestación colectivas opuestas al individualismo europeo, para simbolizar en ellas relaciones gregarias horizontales y antiracionales — contra la racionalidad cartesiana/positivista- En esta discusión, el concepto generación también juega un rol importante al permitir enfocar de otro modo lo juvenil; la juventud, difícil de fijar y seguir en su evolución, ha podido ser objeto de estudio mediante la noción de generación o generaciones juveniles.

8 Desde esa perspectiva, el autor desarrolla una antropología de la juventud que lo ha llevado a estudiar las formas que ha asumido ésta en sociedades precapitalistas occidentales y no occidentales, y en sociedades capitalistas, concentrándose en pijos, progres, posmodernos, chavos banda, punks, entre otras expresiones juveniles de Cataluña y México (Feixa, 1988 y 2006), entornos ubicados en un momento posindustrial.

${ }^{9}$ En el presente, en el marco de formas de flexibilidad cultural, diferentes identidades juveniles aparecen como culturalmente maleables, ya no esencialistas. Para el tema de la flexibilidad económica y su impacto en otros ámbitos como el cultural, David Harvey (1998).

${ }^{10}$ Allí tenemos la máxima de "Sexo, drogas y rocanrol" como estigma y reduccionismo cultural de lo que habría definido, o fijado en el imaginario colectivo, a la juventud internacional surgida hacia los años sesenta del siglo 
XX, con las prácticas emergentes contraculturales de la juventud estadounidense.

${ }^{11}$ Esta tipología tiene un símil en el trabajo de Jesús García Flores (2004), quien propone los modelos de juventud el bueno, el malo y el feo para hablar de tipos de juventud fomentada, proscrita y tolerada. Mediante esa tipología, García Flores describe una interesante dinámica juvenil en la que interactúan estudiantes, porros y jóvenes socialmente poco visibles, asociada con instituciones públicas y valoraciones sociales en esos tres sentidos en la historia moderna del estado de Veracruz.

${ }^{12}$ Que son "rechazadas por los sectores dominantes"; cuyo ejemplo del mundo juvenil son los beatniks, pachucos, hippies, cholos, punks, chavos banda y funkies.

${ }^{13}$ Que no mueven al rechazo o toma de posición frente a ellos por parte de "los sectores fundamentales de la sociedad global" (Valenzuela, 2009).

${ }^{14}$ Se trata de "agrupaciones estimuladas y apoyadas por los grupos dominantes", categoría que ejemplifica con "asociaciones juveniles insertas en las estructuras de los grupos detentadores del poder religioso, político o económico, tales como las juventudes de los partidos políticos en el poder, las asociaciones de jóvenes católicos, rotarios, leones, cámaras junior, etc." (Valenzuela, 2009: 42). Todas ellas clave en tanto medios "para el relevo generacional de los grupos dominantes."

${ }^{15}$ Además de la diversidad cultural del estado asociada con culturas históricas y tradicionales populares, también observamos manifestaciones juveniles inéditas hasta hace poco, protagonizadas por jóvenes pertenecientes a culturas parentales y étnicas de raíz mesoamericana que cumplen con trayectorias de cruce de fronteras simbólicas. Provenientes de la intensa interculturalidad que experimenta el mundo indígena en tiempos de globalización, se reporta la presencia de identidades juveniles rockeras, punks, dark y grafiteras en lugares como la sierra de Zongolica, el Totonacapan y el Istmo veracruzano.
${ }^{16}$ La consideración de tradicional de esta expresión obedece al fondo histórico del que provienen el son jarocho y su fiesta comunitaria del fandango, complejo que suma tres siglos (Delgado, 2004). En el presente, la movilidad espacial y cultural derivada de las migraciones, el uso e integración a sus vidas de Internet (sobre todo por parte de jóvenes), así como las dinámicas de la interculturalidad, han jugado un papel importante en la revitalización y expansión del son y el fandango mucho más allá de su región cultural originaria. Para el tema del carácter juvenil que predomina en la fase actual del son jarocho, integrado dentro del proceso de revitalización cultural denominado Movimiento Jaranero, véase Ávila (2009).

${ }^{17}$ La información que nutre la escena rocanrolera y rockera de Xalapa proviene del trabajo etnográfico de Ávila (2001).

${ }^{18}$ García (2008) recupera parte de su historia oral desde fines de los años cincuenta del siglo XX, esto es, que el rock en México, al menos hasta los años ochenta, fue satanizado, censurado y reprimido. En su camino dentro del panorama cultural nacional "siempre se ha visto maniatado de pies a cabeza: desde sus inicios se le ha manipulado con fines expresamente comerciales y cuando ha tomado posición como parte del desarrollo de una cultura alterna a la hegemónica es cuando los grupos dominantes se ponen en alerta cerrándole las pocas opciones que ha experimentado en el transcurso de los últimos cincuenta años." (García, 208: 75). Otros autores también documentan la represión a la juventud rockera todavía en los años ochenta. Para un ejemplo, entre otros, véase Monsiváis (2012).

19 Se llama así a pequeños comercios que no son propiamente cantinas o bares, aunque se les parecen mucho; allí, además de bebidas alcohólicas, también tienen lugar representaciones culturales.

${ }^{20}$ Un caso aún no del todo reivindicado es la obra de Toño Quirazco, quien a mediados de los años sesenta se convierte en precursor del ritmo ska en el país. Hoy 
en día podemos acercarnos a su obra gracias a Youtube. Un ejemplo lo tenemos en http://www.youtube.com/ watch?v=3XKIjmNemGk.

21 En Ávila (2001), encontramos voces de rockeros xalapeños de diferentes generaciones y periodos que hablan de ese distanciamiento y hasta desconocimiento entre el rock/los rockeros y un Estado que muchas veces sólo se hizo presente ante el joven como sistema policiaco represor. Esta visión antiestatal del rock no es privativa del rockero xalapeño del siglo pasado ha sido documentada por diferentes autores, entre otros Zolov (2004) y Urteaga (1998).

22 Están documentadas acciones de rechazo al rock en diferentes latitudes continentales, así como la oposición a él mediante el aliento político-estatal de nuevas expresiones musicales. En el primer caso, podemos citar la marcha contra la guitarra eléctrica - símbolo de la rebeldía del rock y de la penetración cultural - realizada por jóvenes brasileños hacia la segunda mitad de los años sesenta y a favor de la música popular brasileña (Calil y Terra, 2010); en el segundo, Pacini, Fernández y Zolov (2004) exponen que la trova cubana fue un proyecto del Estado cubano opuesto a la penetración del rock en la isla. En el ámbito nacional también se ha registrado la censura y rechazo al rock y la persecución del rockero sobre todo entre los años sesenta y ochenta (entre otros, Arana, 2002; Urteaga, 1998; José Agustín, 1996). A nivel local más bien se habla de falta de espacios para el rock y, a veces, de censura explícita mediante la cancelación ocasional de comercios donde se tocaba rock (Ávila, 2001). En la escena local impera la percepción por parte de los rockeros de un ambiente antijuvenil y antirockero.

${ }^{23}$ Es de mencionar que no fue sino hasta los años 90, y sólo durante algún tiempo, cuando en un programa estatal, como el Programa de Apoyo a las Culturas Municipales y Comunitarias (Pacmyc), se incluye explícitamente el rock entre los temas culturales posibles para recibir su apoyo.
${ }^{24}$ La región Sotavento es el territorio de origen del son jarocho y el fandango. Desde inicios del siglo XX, la política cultural federal ha organizado su intervención a partir de delimitar diferentes regiones culturales. La del Sotavento incluye una mayoría de municipios del sur del estado de Veracruz, algunos más del de Oaxaca y tres de Tabasco, sus entidades vecinas. En la definición de esta región cultural, la música de son y la fiesta del fandango jarochos, han sido elementos sustantivos.

${ }^{25}$ En Ávila (2008) y en Delgado (2004) encontramos nuevas denominaciones que intentan capturar la diversidad/complejidad de actores del son. Así, xalaparochos son losfandangueros de Xalapa; antroposones, dice Calderón, son profesionales de las ciencias sociales identificados con son y fandango; jarochicanos nombra a losfandangueros chicanos y jarochilangos a los del Distrito Federal... Para un acercamiento a la composición juvenil del Movimiento Jaranero, Ávila (2009).

${ }^{26}$ La recuperación histórica del son en la ciudad apenas comienza, ejemplo de ello es el trabajo de Zoila Martínez Cortés. http://observatorioculturalveracruz.blogspot. mx/2009/06/xalapa-son-jarocho-y-fandango.html.

27 Compuesto al principio por Ramón Gutiérrez Hernández, Laura Rebolloso Cuellar, Juan Francisco Galván, Aracely Galván Cruz, Rubí Oseguera Rueda y Tereso Vega Hernández, junto con Darmacio Cobos y el investigador chileno de la UV Octavio Rebolledo Kloques. Debe indicarse que Honorio Robledo también tocó son jarocho durante los primeros años ochenta en la ciudad. Recientemente, Gilberto Gutiérrez, de Mono Blanco, grupo insignia de la revitalización de son y fandango, formado al final de los años setenta en ciudad de México, dice haber hecho trabajo para posicionar el son en Xalapa, pero la recuperación de esa labor aún está pendiente.

28 Este antiguo patio de vecindad que aún cumple tal función, en décadas atrás una parte de él fue administrado por el Instituto Veracruzano de Cultura (IVEC) y hoy por el ayuntamiento de Xalapa. En los primeros años noventa cuando lo administró el IVEC, 
se instaló allí el taller de laudería de Ramón Gutiérrez, se comenzaron entonces a impartir talleres relativos al son jarocho (jarana, requinto, zapateado, construcción de instrumentos) y a celebrarse maratonianos y masivos fandangos; repitiendo la estrategia de refuncionalización cultural que el Instituto impulsó mediante su sistema de casas de cultura desde su creación en 1987. La importancia del Patio es clave para el movimiento jaranero local. En el presente, la parte que no es de uso habitacional está manejada bajo la figura de comodato por parte del ayuntamiento y es aún utilizada por instructores de artes y oficios que mantienen allí sus talleres; sin embargo, en el trienio actual (20112013) los vecinos inciden en las decisiones sobre uso del espacio - que semeja el de un salón de eventos en renta - y forman parte de la organización y vigilancia de los eventos que deciden abrigar allí (Méndez, 2002).

29 Ésta es una modalidad creada por el movimiento jaranero que integra la faz artística (los grupos dan conciertos tal cual) y la festiva-comunitaria (realizan fandangos donde aquellos que en el concierto eran espectadores o público ahora se integran a la fiesta.

${ }^{30}$ Su labor se da en el registro de estudiosa e investigadora del son en general y de los estilos de zapateado dentro de las subregiones en las que a su vez se desagrega el Sotavento (cuenca del Papaloapan, los Tuxtlas, el Tesechoacán, Los Llanos).

${ }^{31}$ De hecho, hoy se cocinan infinidad de experimentos que intentan hibridar esa música con otras como el rock, el jazz o el reggae. Estas experimentaciones y concreciones tienen en la ciudad de Xalapa un entorno "amable", pues se trata de un contexto donde hace décadas se vive una práctica musical variada.

32 Esta movilización cultural prorevitalización del son y el fandango jarochos surgida hacia finales de los años setenta, se ha centrado en la realización de talleres, seminarios, campamentos-seminarios, conciertos, giras artísticas, grabación de discos y documentales. Tanto el Estado mediante políticas culturales, como el mercado, vía lógicas comerciales de la cultura, han jugado un papel importante en el devenir contemporáneo del son jarocho, en el que la gestión ciudadana ha sido igualmente relevante.

${ }^{33}$ Desde hace casi una década, el grupo Yahooamigos del son jarocho, administrado por Rafael Figueroa Hernández, ha sido espacio que dinamiza el lado virtual de la comunidad fandanguera. Por él pasan acuerdos y disonancias, comunicaciones e intercambios que toda colectividad activa. Las comunidades virtuales y las redes sociales ligadas a Internet también permiten actos solidarios para la realización de eventos en favor de continuar los ciclos festivos del son, como ha sido el caso de la convocatoria de apoyo a la causa del Festival del Tesechoacán 2012. Véase: http://www.kickstarter.com/projects/festivaltesechoacan/ an-ancient-music-festival-comes-to-life.

34 Seguimos la definición del diccionario de la Real Academia de la lengua: "Conjunto de rasgos y modos de comportamiento que conforman el carácter o la identidad de una persona o una comunidad."

\section{Bibliografía}

Ávila Landa, Homero (2001), "Historia del rocken Xalapa: 1960-1995", tesis de licenciatura de la Facultad de Antropología de la Universidad Veracruzana. Xalapa, Veracruz.

Ávila Landa, Homero (2008), "Políticas culturales en el marco de la democratización. Interfaces socioestatales en el movimiento jaranero de Veracruz, 1979-2006", tesis doctoral del CIESAS, México.

Ávila Landa, Homero (2009), "Generaciones juveniles, políticas culturales y revitalización del son y el fandango jarochos. La confluencia entre sociedad y estado en el movimiento jaranero", en Palacio, Celia del (coord.), Los nuevos objetos culturales en Iberoamérica, México: Universidad Veracruzana, pp. 159-210.

Arana, Federico (2002), Guaraches de ante azul, Guadalajara: María Enea.

Calil, Ricardo y Renato Terra (2010), "Uma noite en 67", en Record Entertainment, Video Filmes, Documental. 
Clifford, James (2008), Itinerariostransculturales, Barcelona: Gedisa.

Cruz Salazar, Tania (2003), "Voces de colores. Graffers, crews y writers: identidades juveniles en el defeño metropolitano", tesis de maestría del CIESAS.

Delgado Calderón, Alfredo (2004), Historia, cultura e identidad en el Sotavento, México: Conaculta.

Delgado Calderón, Alfredo (1999), "El impacto regional", en Conaculta, DGCP, A fin de siglo: Una década de cultura popular. Memoria 1989-1998, México: Programa de Apoyo a las Culturas Municipales y Comunitarias (Pamyc), pp. 83-93.

Domínguez (El abuelo), Paco (2012), La historia de Los Rebeldes del Rock, México: Grupo Editorial Tomo.

Feixa Prampols, Carles (1988), La tribu juvenil. Una aproximación transcultural a la juventud, Turín: Edizioni L'Ochiello.

Feixa Prampols, Carles (2006), De jóvenes, bandas y tribus, Barcelona: Editorial Ariel.

García, Bernardo y H. Guadarrama (2002), "15 años por la cultura de Veracruz (El IVEC de 1987 a 2002)", material manuscrito.

García Flores, Jesús (2004), "De tu casa a la escuela...: Modelos de estudiante para uso de jóvenes y adultos en Veracruz", ponencia presentada en el coloquio del CIESAS-Golfo: Juventud: siluetas para armas, Xalapa, 17-18 de junio.

García Ledesma, Jorge (2008), El camino triste de una música. El blues en México y otros textos de blues, México: Ediciones La Cuadrilla de la Langosta.

Giménez, Gilberto (2009), Identidades sociales, México: Conaculta/Instituto Mexiquense de Cultura.

Gomezjara, Francisco, et al (1993), Pandillerismo en el estallido urbano, México: Fontamara.

Harvey, David (1998), La condición de la posmodernidad. Investigación sobre los orígenes del cambio cultural, Buenos Aires: Amorrortu.

José Agustín (1996), La contracultura en México. La historia y el significado de los rebeldes sin causa, los jipitecas, los punks y las bandas, México: Grijalbo.
León, Fabricio (1985), La banda, el consejo y otros panchos, México: Grijalbo.

Levi, Geovanni y Jean-Claude Schmitt (coord.) (1996), Historia de los jóvenes. De la Edad Antigua a la Edad Moderna, 2 vols. Madrid: Taurus.

Maffesoli, Michel (2004), El tiempo de las tribus. El ocaso del individualismo en las sociedades posmodernas, México: Siglo XXI.

Martínez Ríos, Julio (2010), iArde la calle! Emo, punk, indi y otras subculturas en México, México: Random House Mondadori.

Méndez Lugo, Luis Adolfo, "Conservación del patrimonio cultural: El Patio Muñoz", http://mendezlugo. blogspot.mx/2007/02/el-patio-muoz.html. [consulta: 20 de mayo de 2012].

Monsiváis, Carlos (1986), "La naturaleza de la onda", en Amor Perdido, México: SEP, pp. 225-262.

Monsiváis, Carlos (1988), "Dancing: El Hoyo fonqui", en Escenas de Pudor y Liviandad, México: Grijalbo, pp. 233 244.

Monsiváis, Carlos (2012), "La hora del consumo alternativo. El Tianguis del Chopo", en Los rituales del caos, México: ERA, pp. 120-124.

Pacini Hernández, Deeborah, Héctor Fernández L'Hoeste y Eric Zolov (eds.) (2004), Rockin' Las Américas. The Global Politics of Rock in Latin/o America, Pittsburgh: University of Pittsburgh Press.

Palacios, Julia E. (2004), "Yo no soy un rebelde sin causa... O de cómo el rock and roll llegó a México”, en Pérez Islas, José Antonio y Maritza Urteaga Castro-Pozo (coord.), Historias de los jóvenes en México. Su presencia en el siglo XX, México: Instituto Mexicano de la Juventud/ SEP/AGN, pp. 321-348.

Rinaudo, Christian (2011), "Lo 'afro', lo popular y lo caribeño en las políticas culturales de Cartagena y Veracruz", en Ávila Domínguez, Freddy, Ricardo Pérez Montfort y Christian Rinaudo, Circulaciones culturales. Lo afrocaribeño entre Cartagena, Veracruz y La Habana, México: CIESAS/IRD/ANR, Universidad de Cartagena y El Colegio de Michoacán, pp. 3767. 
Urresti, Marcelo (edit.) (2008), Ciberculturas juveniles: los jóvenes, sus prácticas y sus representaciones en la era de Internet, Buenos Aires: La Crujía.

Urteaga Castro-Pozo, Maritza (1998), Por los territorios del rock, México: Causa Joven, CIEJ/CNCA/DGCP.

Valenzuela Arce, José Manuel (1988), A la bravaése! Cholos, punks, chavos banda, Tijuana: El Colegio de la Frontera Norte.

Valenzuela Arce, José Manuel (2009), El futuro ya fue. Socioantropología de las/losjóvenes en la modernidad, México: El Colegio de la frontera Norte/Casa Juan Pablos.
Zebadúa Carbonell, Juan Pablo (1999), "Rock y contracultura. La apropiación cultural del rock por parte de la juventud de los noventa", tesis de licenciatura en Antropología Social, Universidad Veracruzana, Xalapa, Veracruz.

Zolov, Eric (2004), "La Onda Chicana. Mexico's Forgotten Rock Contreculture", en Pacini Hernandez, Deborah, Héctor Fernández L'Hoeste y Eric Zolov, Rockin' Las América. The Global Politics of Rock in Latin/o America, Pittsburgh: Universitu of Pittsburh Press, pp. 22-42. 